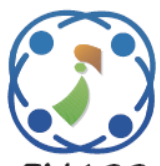

\title{
Timer Based Optimized Clustering for Lifetime Enhancement in WSN
}

\author{
Monika Rajput ${ }^{1 *}$ \\ Sanjay Kumar Sharma ${ }^{1}$ \\ Pallavi Khatri \\ ${ }^{1}$ Department of Computer Science, Banasthali Vidyapith, Rajasthan, India \\ ${ }^{2}$ Department of Computer Science and Engineering, ITM University, M.P., India \\ * Corresponding author's Email: monika.rajput03@yahoo.com
}

\begin{abstract}
The energy of a wireless sensor network is crucial. Energy optimization is one of the key areas where research is being conducted. The upgraded technology in wireless sensor network (WSN) protocols has been seen tending towards clustering of nodes for energy optimization. Sensor nodes are battery- operated, so the size of the WSN matters mainly in terms of energy and the lifespan of the network. This work proposes a new approach of clustering process for energy efficiency in WSN thereby increasing the network lifetime. The initial clustering uses $\mathrm{K}$-medoid, and setup phase using timer-based execution of adaptive neuro-fuzzy inference system (ANFIS). The ANFIS neuron structure is optimized using the firefly algorithm. The timer-based call of ANFIS for re clustering process is the novel approach and shows optimum efficiency in energy consumption. The optimum choice of cluster head $(\mathrm{CH})$ selection leads to uniform energy consumption amongst all the sensor nodes and avoids energy run out problem when $\mathrm{CH}$ charge is given to particular node the performance evaluation shows improvement in energy efficiency and lifetime of the network. This work shows that the lifetime of the network is enhanced by $4 \%$ as compared to existing methods.
\end{abstract}

Keywords: LEACH, WSN, Firefly, ANFIS, Clustering, Optimization, Timer, Routing.

\section{Introduction}

In wireless sensor network applications may include temperature, moisture, air quality, or any data that include periodic sensing and updating towards the data collection center. The data collecting node called as Sink node processes the data to represent as per requirement set in user interface provided. The data collection at the sink node involves a huge amount of activity and mostly wireless sensor networks are battery operated. In such networks, it is necessary to achieve maximum efficiency in terms of energy consumption for the longer life of the entire network being in operating mode.

Low-energy adaptive clustering hierarchy (LEACH) [1] protocol is a self-routing protocol specially designed for WSNs. The dynamic cluster head selection and achieving uniform energy consumption for the maximum lifetime of the network are the fundamental requirements of the protocol. While performing the dynamic clustering based on energy levels of the sensor nodes and respective distance of such nodes from sink nodes or base stations are the important factors considered. It is important to consider the energy consumption of the cluster head $(\mathrm{CH})$ chosen from the set of sensor nodes which is responsible for handover the data towards the sink node from all the sensor nodes associated with it. Also, if the distance of a particular $\mathrm{CH}$ is large from the base station then the energy required to communicate directly with the base station (BS) is also large and hence early death of CHs may have occurred. Also, sensor node which is having less residual energy and if picked as $\mathrm{CH}$ then early death of $\mathrm{CH}$ is possible and hence proper choice of $\mathrm{CH}$ an important factor to increase the energy efficiency. LEACH performs neighborhood information combination to "pack" the measure of information being sent from clusters to the BS, minimizing energy consumption and lifetime enhancement [2]. Sensors participate to become $\mathrm{CH}$ by comparing their energy levels with neighboring 
sensor nodes. After becoming $\mathrm{CH}$, communication with other $\mathrm{CHs}$ is performed to handover the status information. Each $\mathrm{CH}$ of clusters decides the next $\mathrm{CH}$ election attempt till the time all the sensor nodes remain either in idle state or in sensed data generation state. During this state, $\mathrm{CH}$ collects the data from all the sensor nodes and forwards it towards BS [3]. When BS is at a higher distance, it requires either higher transmission energy or involvement of other $\mathrm{CHs}$ in the route as forwarding nodes.

This research work is based on the work done in [4]. The zonal fragmentation of the WSN and forming small clusters by selecting $\mathrm{CHs}$ for each zone is fundamental operation followed. The clustering, $\mathrm{CH}$ selection, and selection attempt regularization is the main objective considered for increasing energy efficiency of the network.

The main characteristic feature of the proposed method is the optimization of the number of attempts in cluster head selection and hence reduces the new $\mathrm{CH}$ selection overhead. Also, the timerbased approach makes the algorithm perform $\mathrm{CH}$ selection at the right time. This ensures the conservation of energy of $\mathrm{CHs}$ and avoiding completely run out of energy of particular $\mathrm{CH}$. This leads to the saving of the number of nodes from death.

This article is organized as follows: Section 1 is Introduction, Literature survey of the existing methods is being presented in section 2, Section 3 details the proposed work and methodology and experimental setup for the same if presented in section 4. Section 5 exhibits the results and discusses them with concluding remarks in section 6 .

\section{Literature review}

The author has proposed an extension of TLLEACH (ETL-LEACH) in [3]. This protocol is based on an improved $\mathrm{CH}$ selection method to improve the energy efficiency of TL-LEACH. The results show that the ETL-LEACH performs better in terms of energy efficiency.

In [5], the author has proposed a protocol named MET-LEACH concerning the LEACH. The METLEACH utilizes the data of the current battery energy level to pick the CHs. The performance evaluation shows improvement by MET-LEACH working strategy.

Researchers have shown the use of particle swarm optimization to improve the LEACH protocol in [6]. The $\mathrm{CH}$ selection attempt optimization is seen as an outcome that increases energy efficiency over basic LEACH protocol.
Researchers have given the study about an improved LEACH show named LEACH with Dijkstra's Algorithm (LEACH-DA) in [7]. The use of a distance-based routing algorithm shows improvement in energy efficiency. The middle point is selected as $\mathrm{CH}$ with respect to traffic level in the network.

In [8], the author gives the study of LEACH and LEACH-GA. Genetic algorithm-based LEACH protocol is optimized. The approach is similar to PSO, shows improvement compared to PSO is seen in GA based approach.

In [9], the author demonstrated the multi-hop communication and clustering a modified version of LEACH. The cross-layer approach of the improvement shows improvement of the medium access layer and routing layer while improving LEACH. The structural delays are reduced due to improvement in protocol along with energy efficiency.

Researchers have provided a method for optimizing ANFIS with the use of the firefly algorithm in [10]. The method shows improvement in processing in terms of accuracy and optimization of neurons which reduces the complexity as well.

Sambo [11] has discussed various load balancing methods for large WSNs. The discussion highlights the significance of fuzzy logic and optimization methods while performing clustering to establish hierarchical WSN.

Jadoon [12] has compared zone-based routing with hierarchical routing which shows better performance for energy efficiency. The article highlights the limitations of hierarchical routing.

In [13], the author has talked about EnergyAware Multi-bounce Routing (EAMR) convention has most essentially accomplished of diminishing the unnecessary overhead. The exhibition investigation shows that overhead decrease altogether improves the lifetime as energy utilization in the sensor hubs can be diminished through an energy productive convention.

The researcher proposed an algorithm called Dynamic Energy Efficient Distance Aware (DEEDA) in [14]. The algorithm is used for the Energy Efficient Cluster choice components in the WSN.

The author proposed an energy-aware disseminated grouping directing convention for EHWSNs; it takes the hub current remaining energy to predict the next $\mathrm{CH}$ in [15]. The proposed steering calculations are contrasted and LEACH as far as the number of conscious hubs and system throughput.

In [16], the researcher has defined the development of direction finding the procedure with 
its significant characterization for remote sensors organization. The description is proposed into four principle plans: Network Structure Scheme, Communication Model Scheme, Topology Based Scheme, and Reliable Routing Scheme.

In wireless sensor network load balancing while aggregating the data is the most important factor considered to increase the overall network efficiency [17]. The method consists of neuro-fuzzy based cluster head selection along with load balancing amongst the sensor nodes. The performance evaluation shows the improvement in the results. The forming tended to here is in the perspective on utilizations and alterations in LEACH proposed by different experts for energy ability in WSN. The conversation gives a brief partner and heading with the contemplations of packaging approach for the enhancement in execution while utilizing $\mathrm{LEACH}$ appear in Wireless sensor arrange.

Work done by Ansam in [18] presents an efficient EESAA protocol for improving the quality of service of WSN. The load balancing-based EESAA protocol is composed of a load estimation mechanism based on the medium sensing principle. The protocol shows efficiency in terms of alive nodes, dead nodes compared to the basic LEACH protocol.

Eyman [19] developed an EESRA protocol for WSN. The network size is taken into consideration along network lifetime enhancement is considered. The performance is evaluated in terms of dean nodes, alive nodes, and residual energy and also compared with the basic LEACH protocol. The protocol shows improvement.

M-IWOCA protocol for WSN lifetime enhancement is proposed by Richa [20]. The protocol consists of an optimization algorithm based on weed optimization in which clustering is optimized for the selection of $\mathrm{CH}$ and the right candidate selection process. The node with maximum residual energy is selected as $\mathrm{CH}$. The performance is evaluated and compared with basic the LEACH protocol. After an exhaustive survey of the literature following limitations could be seen:

1. No consideration to the number of $\mathrm{CH}$ selection attempts which may keep network nodes busy in $\mathrm{CH}$ selection tasks.

2. Large networks where the distance between sensor nodes, and distance of sensor nodes for to the base station is large such that energy required for transmission and reception of packets is higher compared is not taken into consideration. Large distances lead to more energy consumption and hence the early death of the nodes and affects the lifetime of the network.
3. The criteria for the selection of $\mathrm{CH}$ during the election process should be done with respect to the distance of elected $\mathrm{CH}$ and $\mathrm{BS}$ and the distance of one $\mathrm{CH}$ from another $\mathrm{CH}$. This can lead to optimizing network energy consumption when considered in the right fashion and can improve the lifetime.

This work proposes a Hybrid Multilevel Multihop Leach Protocol (HM2LP) to make the network more energy efficient. The proposed protocol is developed to address solutions over limitations identified above in the existing protocol.

\section{Proposed work}

This work proposed a protocol that takes Energy efficiency for a multilevel multihop configured network that leads to more energy consumption in the case of large networks. Energy consumption is the main issue in the WSN.HM2LP is proposed by modifying the basic LEACH protocol to achieve energy efficiency here to make the network more energy efficient. Firstly $\mathrm{CHs}$ are selected by using K-medoid [21] algorithm and make the clusters accordingly. When the energy of the $\mathrm{CH}$ goes below the minimum energy then reselection of $\mathrm{CH}$ will process by using ANFIS parameters which are given below and applied the timer to the selected $\mathrm{CH}$. Firstly reselection will be applied only to that particular cluster in which the energy of the $\mathrm{CH}$ is low as compared to the minimum energy after that reselection of $\mathrm{CH}$ is done according to the timer value. A timer is applied to the $\mathrm{CH}$ to make it more energy-efficient. Right now techniques named ANFIS [22] based $\mathrm{CH}$ and member of the cluster (CM) selection method is described.

In ANFIS based $\mathrm{CH}$ and $\mathrm{CM}$ choice system, the primary spotlight is on the following highlights:

1. The closeness of the BS and different $\mathrm{CHs}$ by considering physical distance

2. Remaining energy

3. Earlier burden (traffic load)

4. Energy level threshold

The ANFIS is used for $\mathrm{CH}$ selection in which the first network is divided into clusters. The Assumptions are set while building up the new methodology which is portrayed underneath. The main contribution of this work is to modify the clustering process by considering various factors that affect energy efficiency. The parameters such as distance, load, and energy threshold together with optimized processing are the main novelty of this work compared to other existing methods. 


\subsection{Firefly-ANFIS}

Optimization of the ANFIS model is feasible by optimizing the number of neurons in the ANFIS network [10]. The main objective behind using ANFIS along with firefly is to optimize the neural network in ANFIS similar to the method in [4]. The meta-heuristic firefly algorithm is explained [23]. The improvement is performed with the use of root mean square error (RMSE). Each firefly includes a great deal of harbinger and resulting parameters. The expected vector of data factors $(x 1, x 2, x 3$, and $x 4)$ and a yield variable $(y)$ in fictional form and using three fleecy sets with Gaussian-type investment limits given in Eq. (1).

$$
y s=P s x 1+q s \times 2+k s x 3+t s x 4+r s
$$

Where, $P, q, k, t$, and $r$ parameters used for biasing the elements.

The average energy is calculated using Eq. (2),

$$
E_{i}=E / D^{2}
$$

Where, $\mathrm{D}$ is the distance from $\mathrm{CH}$.

Selection of nearest $\mathrm{CH}$ is done by using Eq. (3),

$$
\beta=\beta_{0} e^{-\left(D_{c} r^{2}\right)}
$$

Where, $\beta_{0}$ is $\mathrm{CH}$ when distance is zero, $D_{c}$ is the distance of coverage area.

\subsubsection{Firefly algorithm}

1. Determination and initialization of fireflies (initial neurons). Locating the cost function for each species of the neurons in its position.

2. Arbitrary allocation of weights to every neuron.

3. Determination of the finest (brightest) individual of the neurons through the calculation of the cost functions of the entire neurons.

4. Movement of other individuals of the neurons toward the best individual and updating light intensity.

5. Inspection of iteration conditions, in case of iteration conditions, is provided moves in the direction of the next stage, or else moves toward step 4.

\subsection{Hierarchical structure and routing}

The sink node location from a particular $\mathrm{CH}$ may be at a large distance than its coverage area. Due to this sending data towards the sink node may require the addition of other $\mathrm{CH}$ into the path. The shortest path selection mechanism is used to establish a route towards the sink node. The Kmedoid phase is responsible to estimate the distance between all the nodes. The $\mathrm{CH}$ uses this distance information to select the other $\mathrm{CH}$ in route towards the sink node. (4),

The set of distances of each $\mathrm{CH}$ is given in Eq.

$$
D_{s t}=\left\{D_{c h l}, D_{c h 2}, \ldots, D_{c h n}\right\}
$$

Where, $D_{c h l}, D_{c h 2}, \ldots . D_{c h n}$ is distance of each $\mathrm{CH}$ from $\mathrm{CH}$ under consideration.

The selection of min distance $\mathrm{CH}$ is given in Eq. (5),

$$
C H_{\text {sell }}=\min \left(D_{\text {st }}\right)
$$

The routing process should also be carried out with the minimum number of hops in a route. For this purpose, the number of hops information in route towards sink node via first forwarding $\mathrm{CH}$ is used. The number of hops information set can be given in Eq. (6),

$$
H_{s}=\left\{H_{c h 1}, H_{c h 2}, \ldots, H_{c h n}\right\}
$$

The $\mathrm{CH}$ having the minimum number of hops is selected by using Eq. (7),

$$
\mathrm{CH}_{\text {sel2 }}=\min \left(H_{s}\right)
$$

In this scenario, there are two CHs selected with respect to distance and hop count based strategy. This gives rise to two cases.

Case 1: The $\mathrm{CH}$ selected in both cases is identical. The selection ambiguity does not exist in this case and hence normal communication will continue via selected $\mathrm{CH}$.

Case 2: The $\mathrm{CH}$ selected in distance metric and $\mathrm{CH}$ selected in hop metric is different.

In this, case the priority will be given to the hop count metric to keep minimum routing overhead in the network.

Table 1 shows the example of a route established by the $\mathrm{CHs}$ towards the base station when $\mathrm{CHs}$ are

Table 1. Routing structure
\begin{tabular}{|c|c|}
\hline CH node & Routing CH \\
\hline 1 & 10 \\
\hline 10 & 7 \\
\hline 7 & 23 \\
\hline 23 & 43 \\
\hline 43 & 16 \\
\hline 16 & BS \\
\hline
\end{tabular}


not in direct contact with BS due to the large distance in between and specific levels of coverage are. The route towards the base station can be understood as, 1-10-7-23-43-16-BS.

\subsection{CH selection timer}

The $\mathrm{CH}$ selection timer possesses two case scenarios. This timer is responsible for the attempt of the $\mathrm{CH}$ selection process when it expires. If the timer is not expired there will be no attempt of the $\mathrm{CH}$ selection process and hence it continues with existing $\mathrm{CHs}$ for communication.

Case 1: The timer value that is set during the initial stage of the network.

The value of the timer during the initial phase is selected with considerations from experimentation without timer functionality. Normally it is found that the cluster head will run out of energy completely with specific load level $L_{\text {specific }}$ (Eq. (8)). The value of $L_{\text {specific }}$ per second is considered as the maximum load in the specific cluster. The average number of nodes within a specific cluster can be considered as 25. Hence,

$$
L_{\text {specific }}=4000 \times 24(\text { per second })
$$

Where, 4000 is the value of data bytes sent by sensor node during active mode and total of 24 nodes in the cluster except $\mathrm{CH}$ will generate the data which have to send to the sink node.

The rate of energy consumption normally can be estimated by considering Eq. (10). By considering $E_{s}$, The timer value can be estimated by Eq. (9),

$$
T_{\text {initial }}=L_{\text {specific }} \times E_{s}
$$

Case 2: The timer value during the continuous running of the network.

The $\mathrm{CH}$ selection timer value is estimated using $\mathrm{CH}$ load handling capacity. The timer value depends on load handling capacity and energy consumption per second.

The energy consumption per second is estimated by,

$$
E_{s}=E_{\text {old }}-E_{\text {new }} / \text { time_span }
$$

Where, $E_{\text {old }}$ is residual energy for the last round of $\mathrm{CH}$ selection, $E_{\text {new }}$ is residual energy for the current round of $\mathrm{CH}$ selection and time_span Eq. (11) is the time within two $\mathrm{CH}$ selection attempts. The $E_{s}$ which is the rate of energy consumption can be used to estimate the timer value to be set for the $\mathrm{CH}$ selection attempt.

$$
T_{x}=E_{c r} / E_{s}
$$

Where, $E_{\text {cr }}$ is the current residual energy of the selected $\mathrm{CH}$.

Hence load handling capacity of the node is calculated by using Eq. (12),

$$
L_{h}=E_{c r} / L_{o}
$$

Where, $E_{c r}$ is the current residual energy of Selected $\mathrm{CH}$ and $L_{o}$ load of a particular node in the last iteration. This load handling capacity provides the information of last iteration load while selecting a new cluster head.

\subsection{Assumptions}

The energy-efficient LEACH protocol for WSN is the main objective of the development and the assumptions are:

1. In the initialization phase, pre clustering is to be performed.

2. The $\mathrm{CH}$ selection process should be independent of a particular zone.

3. Re selection of $\mathrm{CH}$ should be carried out only in cases when there is a requirement of changing $\mathrm{CH}$.

4. Previous traffic load along with the next $\mathrm{CH}$ selection process triggering should be based on time estimations.

The two-phase clustering approach based on the assumptions above can be detailed as, Setup phase and the $\mathrm{Re}-\mathrm{CH}$ selection phase.

\subsection{Setup phase}

In the setup, phase $\mathrm{CHs}$ are select by using $\mathrm{K}$ medoid as per Algorithm 1 and make the clusters accordingly.

\subsection{Applying K-medoid}

a. In K-medoid based bunching, firstly arbitrary hubs are chosen as $\mathrm{CH}$.

b. The chosen $\mathrm{CH}$ speaks with the hubs that are just in their immediate inclusion zone.

c. The separation built a relationship of regular hubs has associability with just those $\mathrm{CHs}$ which have less good ways from the specific hub.

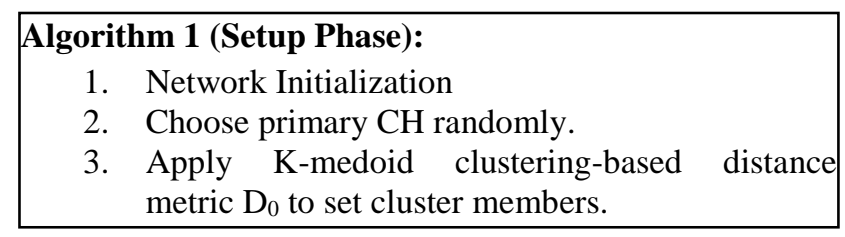


d. Henceforth just less separation are the criteria to turn into a bunch of parts connected with specific $\mathrm{CH}$.

\subsection{K-medoid process}

The K-mediod process is used to find the distance between two sensors $\mathrm{CH}$. Assign cluster membership based on distance criterion.

If $D_{\text {in }}<D_{j n}$ Associate with $i$

Where, randomly selected cluster heads are represented by $i$ and $j$ at the time of the first start phase, $n$ is node common in range for $\mathrm{CHs} i$, and $j$ and $\mathrm{D}$ is the distance calculated by using Cartesian distance formula,

$D_{i n}=\sqrt{\left(x_{i}-x_{n}\right)^{2}+\left(y_{i}-y_{n}\right)^{2}}, D_{j n}=\sqrt{\left(x_{j}-x_{n}\right)^{2}+\left(y_{j}-y_{n}\right)^{2}}$

Where, $\left(x_{i}, y_{i}\right),\left(x_{j}, y_{j}\right)$ and $\left(x_{n}, y_{n}\right)$ are the location coordinates of $\mathrm{CH}_{i}, \mathrm{CH}_{j}$ node respectively.

\subsection{Re-CH selection phase}

The $\mathrm{CH}$ determination process is conveyed just if the clock lapses. The choice of new a $\mathrm{CH}$ should be possible by utilizing ANFIS based strategy. The $\mathrm{CH}$ selection method proposed in Algorithm 2 is responsible for improved collection mechanism of sensor data collection. The enhancement of the bunching procedure in FIS is a piece of ANFIS that should be possible utilizing firefly improvement.

The energy expended is determined and lingering energy level is refreshed in each datum transmission and gathering endeavored by ordinary

\begin{tabular}{|rl|}
\hline Algorithm 2 (Re- CH Selection Phase) \\
1. Is the timer expired? If yes \\
go to step 5 else go to step 4. \\
2. Create a vector of $\mathrm{D}_{0}$, \\
$\mathrm{E}_{\mathrm{c}}$ and distance from other CMs. \\
3. Evaluate load handling \\
capacity ( $\left.\mathrm{L}_{\mathrm{h}}\right)$ with respect to \\
traffic density. \\
4. Select previous traffic based \\
CH to avoid complete run-out \\
of energy for any CH. \\
5. Select new CH based on the previous \\
load, BS distance, and CM distance \\
parameters. \\
6. Re-estimate timer value and set timer for \\
next CH selection attempt. \\
7. Continue for routing of data. \\
8. Go to step 4.
\end{tabular}

hub when separation of the hub is more prominent than the edge esteem is given in Eq. (14),

$$
\begin{aligned}
& E_{c}= \\
& E_{p^{-}}\left(E_{T X} \times(B t)+E_{m p} \times B t x\left(D_{0} \times D_{0} \times D_{0} \times D_{0}\right)\right)
\end{aligned}
$$

Where,

$E_{c}=$ current residual energy

$E_{m p}=$ Transmit amplifier energy

$E_{T X}=$ Required Energy needed to transmit each bit

$\mathrm{D}_{0}=$ Minimum distance for transmission, that is range of communication in normal amplification of the signal.

$E_{p}=$ Previous residual energy

$B t=$ Number of bits

$D_{0}$ (Eq. (15)) is coverage area distance and predictable with current $\mathrm{CH}$ taken for the calculation. The maximum value of $\beta$ is more on attraction to get selected. The distance from BS is calculated by using the Cartesian distance formula.

$$
D_{0}=\sqrt{\left(x_{1}-x_{2}\right)^{2}+\left(y_{1}-y_{2}\right)^{2}}
$$

The energy spent by $\mathrm{CH}$ while receiving the data is given in Eq. (16),

$$
E_{c h}=E_{p^{-}}\left(E_{R X}+E_{D A}\right) \times B t
$$

Where,

$E_{c h}=$ Energy consumed by $\mathrm{CH}$ during reception of data

$E_{p=}$ Previous residual energy

$E_{R X}=$ Energy used up for the reception

$E_{D A}=$ Energy used up for data aggregation

\section{Experiment setup}

The proposed HM2LP protocol is implemented in MATLAB. The configuration used in the experimentation is sown in Table 2.

\section{Results and discussion}

\subsection{Alive nodes and dead nodes}

Fig. 1 and 2 shows the analysis of alive and dead node with respect to iterations. It clearly shows that the number of dead nodes of the HM2LP protocol is less as compared to the EESAA [18], EESRA [19], and M-IWOCA [20] protocols. Hence, the performance of HM2LP in term of alive and dead 
Table 2. Experimental parameters configuration

\begin{tabular}{|c|c|}
\hline Parameter & Value \\
\hline Sensor deployment area (field) & $100 \times 100 \mathrm{~m}^{2}$ \\
\hline Number of nodes & 100 \\
\hline emp & $100 \mathrm{pj}$ \\
\hline Location of the sink node & Center of the field \\
\hline Initial Energy of each node & $5 \mathrm{~J}$ \\
\hline Transmission energy & $50 \mathrm{uJ}$ \\
\hline Reception energy & $50 \mathrm{uJ}$ \\
\hline Data aggregation energy & $5 \mathrm{~nJ}$ \\
\hline Number of data bits & 4000 \\
\hline Protocols & HM2LP, EESAA, EESRA, M-IWOCA \\
\hline Performance Parameters & Number of Alive nodes, Number of Dead nodes, Residual Energy, Consumed \\
& Energy, Network Lifetime \\
\hline
\end{tabular}

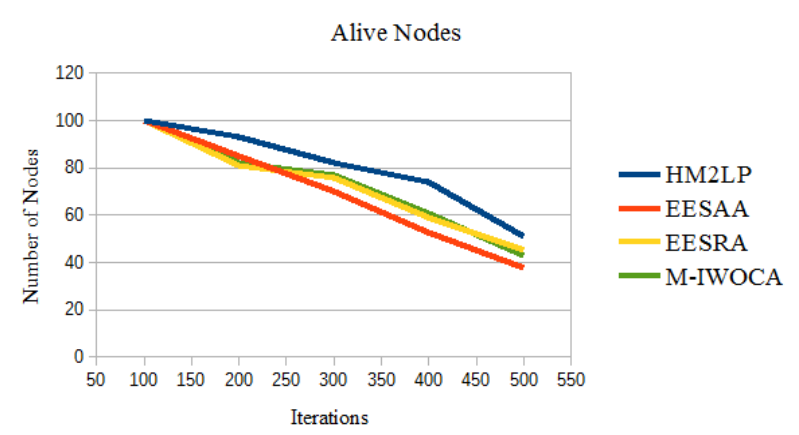

Figure. 1 Comparative analysis of alive nodes with respect to iterations

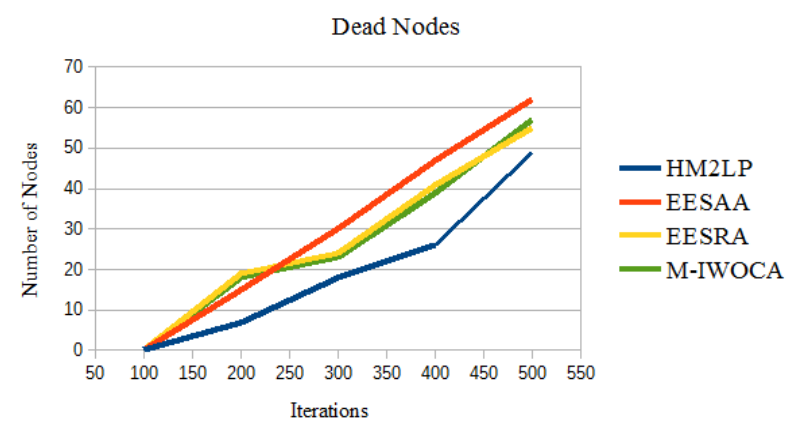

Figure. 2 Comparative analysis of dead nodes with respect to iterations

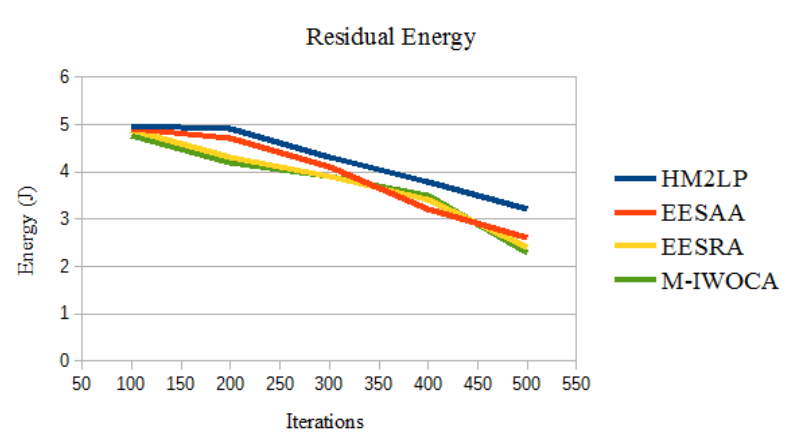

Figure. 3 Comparative analysis of average residual energy

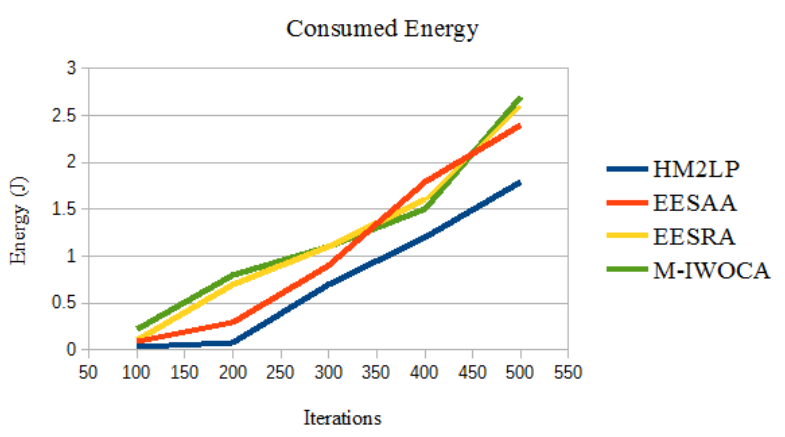

Figure. 4 Comparative analysis of average consumed energy 
nodes is $13 \%$ better as compared to the other three protocols.

\subsection{Average residual and consumed energy}

Fig. 3 and 4 show the analysis of residual and consumed energy with respect to iterations. Based on the simulation analysis HM2LP consumed $29 \%$ less energy as compared to the other three protocols and make the network more energy efficient.

\subsection{WSN lifetime}

Fig. 5 shows the network lifetime analysis. HM2LP method shows better performance in terms of energy efficiency and hence shows more number of nodes alive with respect to iterations than EESAA [18], EESRA [19], and M-IWOCA [20] methods. The lifetime analysis is also performed in which the first node died, the last node died is observed. Based on the result analysis the lifetime of the HM2LP is $4 \%$ improved as compare to the other three protocols.

\subsection{Annotations}

1. The dead node counting analysis shows the number of nodes being dead with respect to iterations is more in normal leach when the field area is $100 \mathrm{~m} \times 100 \mathrm{~m}$. The number of dead nodes in the HM2LP protocol is quite less compared to the other three.

2. The energy efficiency of HM2LP is better than the other three protocols. Also, energy efficiency increases in HM2LP.

The best performing Timer-based method of modified LEACH protocol HM2LP is compared with existing protocols. The protocol HM2LP is developed for a large network size with a high density of nodes in the network. The protocols in

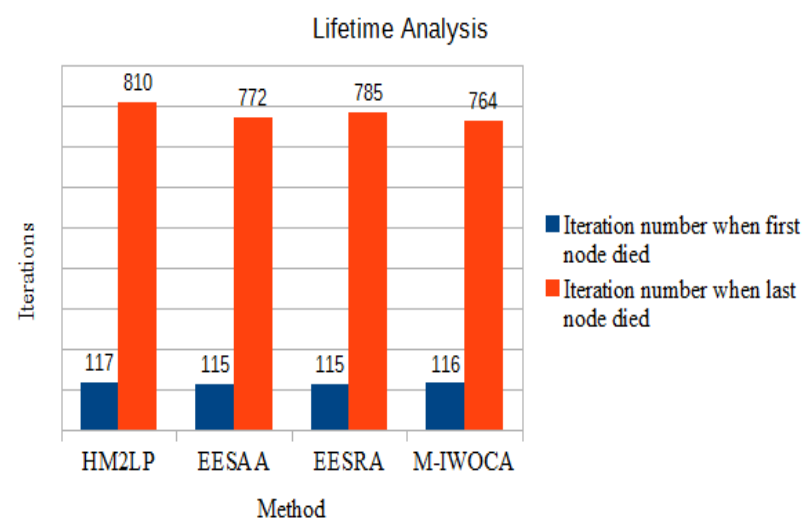

[20-22] have not considered the applicability of large networks and hence HM2LP is configured to work on small networks with small network sizes for comparative analysis. The configuration of the experiment is shown in Table 2.

\section{Conclusions}

This paper contributes in terms of a novel method of LEACH modification using state-of-theart-method of ANFIS and Firefly. The results of LEACH with ANFIS and Firefly optimization with timer shows significantly better performance for energy efficiency and a lifetime of the WSN. The comparison of ANFIS and ANFIS with firefly and ANFIS with firefly timer proves the use and suitability in terms of performance improvement for large wireless sensor network applications. In the use of basic LEACH protocol, the performance significantly degrades as network size goes on increasing. The comparative analysis is done by considering basic LEACH protocol and hence improvements from other researchers are not considered.

The timer function introduced in the method has improved the performance by decreasing $\mathrm{CH}$ selection overhead and decreasing the total number of attempts in the $\mathrm{CH}$ selection process. The end-toend delay performance is compromised in the network compared to LEACH as further addition of ANFIS, Firefly, and timer are done. The main outcome of the method is less complexity in the network and less routing overhead thereby increment in energy efficiency which ultimately improves the total lifetime of the network.

Based on a comparative study with existing methods, HM2LP outperforms over EESAA [18], EESRA [19], and M-IWOCA [20] methods in terms of alive nodes, dead nodes, residual energy, consumed energy, and a lifetime of the network.

\section{Conflicts of Interest}

The authors declare no conflict of interest.

\section{Author Contributions}

Data collection, concept, analysis, methodology, writing - original draft preparation, software, and writing - review, and editing has been done by $1^{\text {st }}$ author. The supervision, review, investigation have been done by $2^{\text {nd }}$ author. The supervision, validation, review, investigation, and writing - review and editing have been done by $3^{\text {rd }}$ author.

Figure 5. Lifetime comparative analysis 


\section{References}

[1] W. R. Heinzelman, A. Chandrakasan, and H. Balakrishnan, "Energy-Efficient Communication Protocol for Wireless Microsensor Networks", In: Proc. of 33rd IEEE International Conference on System Sciences, pp. 1-10, 2000.

[2] A. Yousaf, F. Ahmad, S. Hamid, and F. Khan, "Performance Comparison of Various LEACH Protocols in Wireless Sensor Networks", In: Proc. of the 15th International IEEE Colloquium on Signal Processing \& Its Applications (CSPA), pp. 108-113, 2019.

[3] K. Manzoor, S. H. Jokhio, T. J. S. Khanzada, and I. A. Jokhio, "Enhanced TL-LEACH routing protocol for large-scale WSN applications", In: Proc. of the International IEEE Conference on Cyber security and Cyberforensics Conference (CCC), pp. 35-39, 2019.

[4] M. Rajput, S. K. Sharma, and P. Khatri, "Improvement in LEACH Protocol for Energy Efficiency", International Journal of Innovative Technology and Exploring Engineering, Vol. 9, No. 3, pp. 2063-2069, 2020.

[5] A. Mansura, M. Drieberg, A. A. Aziz, and V. Bassoo, "Multi-Energy Threshold-based Routing Protocol for Wireless Sensor Networks", In: Proc. of the 10th International IEEE Conference on Control and System Graduate Research Colloquium (ICSGRC), pp.71-75, 2019.

[6] H. Ahmed, C. O. Erciyes, W. M. Lafta, and M. A. Nasif, "Optimization Clustering Routing Techniques in Wireless Sensor Networks", In: Proc. of the 2nd IEEE Conference on Scientific Conference of Computer Sciences (SCCS), pp. 28-31, 2019.

[7] A. Rafi, A. Rehman, G. Ali, and J. Akram, "Efficient EnergyUtilization in Fog Computing based Wireless Sensor Networks", In: Proc. of the 2nd IEEE International Conference on Computing, Mathematics and Engineering Technologies (iCoMET), pp. 1-5, 2019.

[8] M. U. H. A. Rasyid, N. R. Mubtadai, and J. Abdulrokhim, "Performance Analysis LEACH Based Genetic Algorithm In Wireless Sensor Network", In: Proc. of the IEEE International Seminar on Application for Technology of Information and Communication (iSemantic), pp. 394-399, 2019.

[9] P. Yarde, S. Srivastava, and K. Garg, "A Delay Abridged Judicious Cross-Layer Routing
Protocol for Wireless Sensor Network", In: Proc. of the 4th International IEEE Conference on Computer and Communication Systems (ICCCS), pp. 634-638, 2019.

[10] R. G. Moghadam, M. A. Izadbakhsh, and F. S. Shabanlou, "Optimization of ANFIS network using firefly algorithm for simulating discharge coefficient of side orifices", International Journal of Applied Water Science, pp. 1-12, 2019.

[11] D. W. Sambo, B. O. Yenke, A. Förster, and P. Dayang, "Optimized Clustering Algorithms for Large Wireless Sensor Networks: A Review", International Journal of Sensors, pp. 1-27, 2019.

[12] R. N. Jadoon, W. Y. Zhou, I. A. Khan, M. A. Khan, S. A. Abid, and N. A. Khan, "Performance Evaluation of Zone-Based Routing with Hierarchical Routing in Wireless Sensor Networks", International Journal of Wireless Communications and Mobile Computing, pp. 1-11, 2019.

[13] K. Cengiz and T. Dag, "Energy Aware MultiHop Routing (EAMR) Protocols for WSNs", IEEE transaction on wireless communication, Vol. 6, pp. 2622-2633, 2018.

[14] M. V. M. K. Maddali and A. Chaparala, "Dynamic Energy Efficient Distance Aware Protocol for the Cluster Head Selection in the Wireless Sensor Networks", In: Proc. of the 2nd IEEE International Conference on Recent Trends in Electronics Information \& Communication Technology (RTEICT), pp. 147-150, 2017.

[15] J. Li and D. Liu, "An energy aware distributed clustering routing protocol for energy harvesting wireless sensor networks", In: Proc. of the IEEE/CIC International Conference on Communications in China (ICCC), pp.1-6, 2016.

[16] A. Solanki and N. B. Patel, "LEACH-SCH: An Innovative Routing Protocol for Wireless Sensor Network", In: Proc. of the IEEE Conference on recent trends in wireless technology, 2013.

[17] P. K. Kashyap, S. Kumar, U. Dohare, V. Kumar, and R. Kharel, "Green Computing in Sensors-Enabled Internet of Things: Neuro Fuzzy Logic-Based Load Balancing", International Journal of Electronics, pp.1-21, 2019.

[18] A. Ennaciri, M. Erritali, and J. Bengourram, "Load Balancing Protocol (EESAA) to improve Quality of Service in Wireless sensor network", 
Procedia Computer Science, Vol. 151, pp. 1140-1145, 2019.

[19] E. F. A. Elsmany, M. A. Omar, T. Wan, and A. A. Altahir, "EESRA: Energy Efficient Scalable Routing Algorithm for Wireless Sensor Networks", IEEE Access, Vol. 7, pp. 9697496983, 2019.

[20] R. Sharma, V. Vashisht, and U. Singh, "Fuzzy modeling based energy aware clustering in wireless sensor networks using modified invasive weed optimization", Journal of King Saud University - Computer and Information Sciences, 2019.

[21] P. Arora, D. Deepali, and S. Varshney, "Analysis of K-Mean and K-medoids Algorithm for Big Data", In: Proc. of International Conference on Information Security and Privacy (ICISP2015), pp. 507-512, 2015.

[22] J. R. Jang, “ANFIS: adaptive-network-based fuzzy inference system", IEEE Transactions on Systems, Man, and Cybernetics, Vol. 23, No. 3, pp. 665-685, 1993.

[23] X. S. Yang, "Firefly Algorithms for Multimodal Optimization", Lecture Notes in Computer Science, 2009.

\section{Appendix}

\begin{tabular}{|c|c|}
\hline Variable & Description \\
\hline $\mathrm{y}$ & Yield variable \\
\hline Ps, qs, ks, ts, rs & Biasing element \\
\hline $\mathrm{x} 1, \mathrm{x} 2, \mathrm{x} 3, \mathrm{x} 4$ & Data factors \\
\hline $\mathrm{Ei}$ & Average energy \\
\hline $\mathrm{E}$ & Initial energy of nodes \\
\hline $\mathrm{D}$ & Distance from $\mathrm{CH}$ \\
\hline$\beta$ & $\begin{array}{l}\text { Firefly attractiveness between } \\
\text { two fireflies }\end{array}$ \\
\hline$\beta_{0}$ & Attractiveness at $\mathrm{r}=0$ \\
\hline $\mathrm{D}_{\mathrm{c}}$ & Distance of coverage area \\
\hline $\mathrm{D}_{\mathrm{st}}$ & $\begin{array}{l}\text { Set of distances of each } \mathrm{CH} \\
\text { (Vector) }\end{array}$ \\
\hline $\mathrm{D}_{\mathrm{ch} 1}, \mathrm{D}_{\mathrm{ch} 2, \ldots .} \mathrm{D}_{\mathrm{chn}}$ & $\begin{array}{l}\text { Distance of each CH from } \\
\mathrm{CH}\end{array}$ \\
\hline $\mathrm{CH}_{\text {sel1 }}$ & $\begin{array}{l}\text { Selected } \mathrm{CH} \text { based minimum } \\
\text { distance }\end{array}$ \\
\hline $\mathrm{H}_{\mathrm{s}}$ & Number of Hops \\
\hline $\begin{array}{l}\mathrm{H}_{\mathrm{ch} 1}, \\
\mathrm{H}_{\mathrm{ch} 2, \ldots \ldots, \mathrm{H}_{\mathrm{chn}}}\end{array}$ & $\begin{array}{l}\text { Number of hops of } \mathrm{CH} 1, \mathrm{Ch} 2 \\
\text { up to } n\end{array}$ \\
\hline $\mathrm{CH}_{\mathrm{sel} 2}$ & $\begin{array}{l}\text { Selected CH based on the } \\
\text { minimum number of Hops }\end{array}$ \\
\hline $\mathrm{H}_{\mathrm{s}}$ & Set of CHs hop count \\
\hline $\mathrm{L}_{\text {specific }}$ & $\begin{array}{l}\text { Specific load level of } \\
\text { complete energy runs out }\end{array}$ \\
\hline
\end{tabular}

\begin{tabular}{|c|c|}
\hline$T_{\text {intial }}$ & Initial timer value \\
\hline $\mathrm{E}_{\mathrm{s}}$ & $\begin{array}{l}\text { Energy Consumption per } \\
\text { second }\end{array}$ \\
\hline Eold & $\begin{array}{l}\text { Residual energy for last round } \\
\text { of } \mathrm{CH} \text { selection }\end{array}$ \\
\hline Enew & $\begin{array}{l}\text { Residual energy for the } \\
\text { current round of } \mathrm{CH} \text { selection }\end{array}$ \\
\hline time_span & $\begin{array}{l}\text { Time within two } \mathrm{CH} \\
\text { selection attempts }\end{array}$ \\
\hline $\mathrm{T}_{\mathrm{x}}$ & Timer value \\
\hline $\mathrm{E}_{\mathrm{cr}}$ & $\begin{array}{l}\text { The current residual energy of } \\
\text { the selected } \mathrm{CH} \text {. }\end{array}$ \\
\hline $\mathrm{L}_{\mathrm{h}}$ & Load Handling capacity \\
\hline $\mathrm{L}_{\mathrm{o}}$ & $\begin{array}{l}\text { The load of a particular node } \\
\text { in last iteration }\end{array}$ \\
\hline $\mathrm{D}_{\text {in }}$ & $\begin{array}{l}\text { Distance between node } \mathrm{n} \text { and } \\
\mathrm{CH}_{\mathrm{i}}\end{array}$ \\
\hline $\mathrm{D}_{\mathrm{jn}}$ & $\begin{array}{l}\text { Distance between node } \mathrm{n} \text { and } \\
\mathrm{CH}_{\mathrm{j}}\end{array}$ \\
\hline $\mathrm{x}_{\mathrm{i}, \mathrm{y}_{\mathrm{i}}}$ & Coordinate of $\mathrm{CH}_{\mathrm{i}}$ \\
\hline $\mathrm{x}_{\mathrm{n}, \mathrm{y}_{\mathrm{n}}}$ & Coordinate of node $n$ \\
\hline $\mathrm{E}_{\mathrm{p}}$ & $\begin{array}{l}\text { Previous round residual } \\
\text { energy }\end{array}$ \\
\hline$E_{c}$ & Current residual energy \\
\hline $\mathrm{E}_{\mathrm{TX}}$ & $\begin{array}{l}\text { Required Energy needed to } \\
\text { transmit each bit }\end{array}$ \\
\hline $\mathrm{Bt}$ & Number of bits \\
\hline$E_{m p}$ & Transmit amplifier energy \\
\hline $\mathrm{D}_{0}$ & Distance \\
\hline $\mathrm{x}_{1,} \mathrm{y}_{1}$ & Coordinates of BS \\
\hline $\mathrm{x}_{2}, \mathrm{y}_{2}$ & Coordinates of $\mathrm{CH}$ \\
\hline $\mathrm{E}_{\mathrm{ch}}$ & $\begin{array}{l}\text { Energy consumed during } \\
\text { reception of data }\end{array}$ \\
\hline$E_{p}$ & Previous residual energy \\
\hline $\mathrm{E}_{\mathrm{RX}}$ & $\begin{array}{l}\text { Energy used up for the } \\
\text { reception }\end{array}$ \\
\hline $\mathrm{E}_{\mathrm{DA}}$ & $\begin{array}{l}\text { Energy used up for data } \\
\text { aggregation }\end{array}$ \\
\hline
\end{tabular}

